\title{
Childhood Poverty, Early Motherhood and Adult Social Exclusion
}

\author{
John Hobcraft and Kathleen Kiernan
}

\section{Contents}

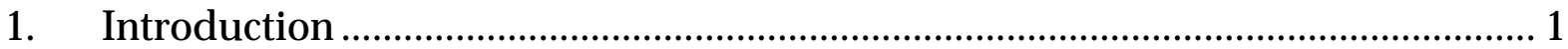

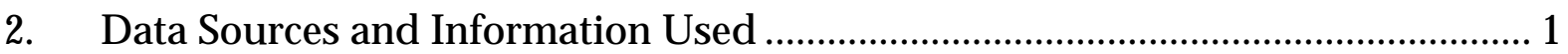

3. Tabular analysis..................................................................................................... 5

4. Does age at motherhood affect adverse adult outcomes? ...................................... 10

5. Consequences of early motherhood and childhood poverty ................................. 15

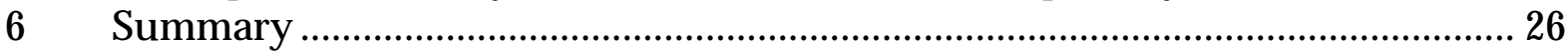

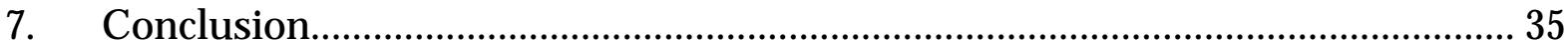

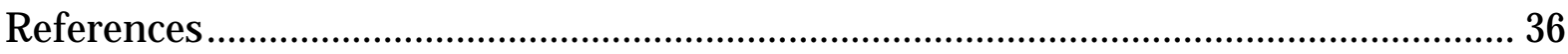

CASEpaper

CASE $/ 28$

July 1999
Centre for Analysis of Social Exclusion

London School of Economics

Houghton Street

London WC2A 2AE

CASE enquiries - tel: 02079556679 


\section{Centre for Analysis of Social Exclusion}

The ESRC Research Centre for Analysis of Social Exclusion (CASE) was established in October 1997 with funding from the Economic and Social Research Council. It is located within the Suntory and Toyota International Centres for Economics and Related Disciplines (STICERD) at the London School of Economics and Political Science, and benefits from support from STICERD. It is directed by Howard Glennerster, John Hills, Kathleen Kiernan, Julian Le Grand, Anne Power and Carol Propper.

Our Discussion Paper series is available free of charge. We also produce summaries of our research in CASEbriefs, and reports from various conferences and activities in CASEreports. To subscribe to the CASEpaper series, or for further information on the work of the Centre and our seminar series, please contact the Centre Administrator, Jane Dickson, on:

$\begin{array}{ll}\text { Telephone: } & \text { UK+20 } 79556679 \\ \text { Fax: } & \text { UK+20 7955 6951 } \\ \text { Email: } & \text { j.dickson@lse.ac.uk } \\ \text { Web site: } & \text { http://sticerd.lse.ac.uk/Case/ }\end{array}$

(C) John Hobcraft

Kathleen Kiernan

All rights reserved. Short sections of text, not to exceed two paragraphs, may be quoted without explicit permission provided that full credit, including $\odot$ notice, is given to the source. 


\section{Editorial Note}

John Hobcraft is Professor of Population Studies in the Department of Social Policy, London School of Economics and Political Science, and a Research Associate in the Centre for Analysis of Social Exclusion. Kathleen Kiernan is Reader in Social Policy and Demography in the Department of Social Policy, London School of Economics and Political Science, and Co-Director of the Centre for Analysis of Social Exclusion.

\section{Acknowledgements}

We would like to thank Louise Dominian and Moira Wallace of the Social Exclusion Unit for inspiring this research and the Department of Health for funding the project. The NCDS data used in this study were supplied by the ESRC Data Archive at Essex University.

\section{Abstract}

Childhood poverty and early parenthood are both high on the political agenda. The key new issue addressed in this research is the relative importance of childhood poverty and of early motherhood as correlates of outcomes later in life. How far are the 'effects' of early motherhood on later outcomes due to childhood precursors, especially experience of childhood poverty? If there are powerful associations of both childhood poverty and early parenthood with later adult outcomes, there are a number of subsidiary questions relating to the magnitude of these associations, the particular threshold levels of childhood poverty that prove most critical, and whether it is, as often assumed, only teenage mothers who are subsequently disadvantaged, or also those who have their first birth in their early twenties? The source of data for this study is the National Child Development Study.

We examine a range of outcomes at age 33 in a number of domains representing different aspects of adult social exclusion, including: welfare, socio-economic, physical health, and emotional well-being, as well as demographic behaviour. We control for a wide range of childhood factors: poverty; social class of origin and of father; mother's and father's school leaving age; family structure; housing tenure; 
mother's and father's interest in education; personality attributes; performance on educational tests; and contact with the police by age 16 .

We show that there are clear associations for the adult outcomes with age at first birth, even after controlling for childhood poverty and a wide range of other childhood background factors. Moreover, we demonstrate that the widest gulf in adult outcomes occurs for those who enter motherhood early (before age 23), though further reinforced for teenage motherhood for most adult outcomes. We also show that it is any experience of childhood poverty that is most clearly associated with adverse outcomes in adulthood, with additional reinforcement for higher levels of childhood poverty only being significant for a few outcomes. Becoming a mother before age 23 and any experience of childhood poverty are clear dividing points in differentiating risks of adverse outcomes in later adulthood. Although the effects of childhood poverty are generally weaker, they nevertheless reinforce the effects of age at first birth to generate sizeable odds ratios for the combination: early mothers who were poor sometime during childhood are over four times as likely to have been a lone parent and to lack a telephone in their household; over three times as likely to live in social housing and to have no qualifications; more than twice as likely to have had an extramarital birth, be claiming non-universal benefits, to be cigarette smokers, and to have high malaise scores. 


\section{Introduction}

Childhood poverty and early parenthood are both high on the current political agenda (HM Treasury 1999; Social Exclusion Unit 1999). There is now a considerable body of evidence from British longitudinal studies that shows that poor girls and those from generally less advantageous backgrounds are more likely to become teenage mothers (Kiernan 1980, 1995, and 1997; Hobcraft 1998). There is also much evidence that those who become teenage mothers have less advantageous outcomes later in adult life (Kiernan 1980, and 1995); and that children with less advantaged backgrounds have poorer outcomes as adults (Wadsworth 1991; Hobcraft 1998; Gregg et al 1999; CASE and HM Treasury 1999).

The key new issue that this research addresses is to try to disentangle the relative importance of childhood poverty and of early motherhood as correlates of outcomes later in life. How far are the 'effects' of early motherhood on later outcomes due to childhood precursors, especially experience of childhood poverty? If there are powerful associations of both childhood poverty and early parenthood with later adult outcomes, there are a number of subsidiary questions relating to the magnitude of these associations, the particular threshold levels of childhood poverty that prove most critical, and whether it is, as often assumed, only teenage mothers who are subsequently disadvantaged, or also those who have their first birth in their early twenties?

\section{Data Sources and Information Used}

The source of data for this study is the National Child Development Study (NCDS). The NCDS is a longitudinal study of children born in the first week in March 1958 for whom a great deal of information was collected during childhood at ages $0,7,11$, and 16 and information on experiences adulthood has been collected on two occasions at ages 23 and 33 (for further details see Ferri et al 1993).

\subsection{Levels of childhood poverty}

The poverty variable used in the analyses is a cumulative measure of five items drawn from waves one to three of NCDS, as used in an earlier study (Hobcraft 1998). At each of these waves it was reported whether the family was 'in financial difficulties'. At age 7 this was one of a series 
of 'family difficulties' reported on by the Health visitor responsible for the interview, with clear instructions that the section should be completed in confidence and without questioning the family. At ages 11 and 16, the parent or other respondent was asked directly 'have you been seriously troubled by financial hardship in the last 12 months?' In addition, at ages 11 and 16, information was collected from the parents concerning whether any child in the family received free school meals. All five of these reports are taken to indicate that the survey member was probably experiencing poverty at or just before the time of the surveys.

From this basic information, we constructed counts of the number of 'yes' and of 'no' responses and then grouped all respondents into 6 categories. The first (labelled 'not poor') corresponds to unequivocal evidence of all five responses existing and being negative. The second ('probably not') takes all cases where one or more responses are missing, but all that do exist are negative. The third group (some poverty) comprises those reporting one 'yes' combined with two to four negative responses. The fourth category (fairly poor) is made up of those reporting one 'yes' combined with zero or one 'no', two 'yes' with one to three 'no' or three 'yes' with two 'no'. The fifth group ('clearly poor') contains those with the clearest indications of poverty, with zero 'no' combined with two or more 'yes' or one 'no' and three or four 'yes'. Finally, the sixth group ('missing all') has no clear response to any of the questions, with all information being either missing or 'don't know'. These groupings were chosen partly for their coherence and partly on the basis of exploratory analyses on other variables. For more details on this measure see Hobcraft, 1998.

\subsection{Other childhood background variables}

As well as a summary measure of poverty during childhood, we also control for a wide range of other background factors which summarised experience through childhood for several key dimensions: these include social class of origin (a combination of the social class of both grandfathers and the father at the time of their birth); social class of father (or father figure) during childhood; mother's and father's school leaving age; family structure (in care, born out-of-wedlock, and combinations of divorce and widow(er)hood with remarriage status); housing tenure; both mother's and father's interest in the child's education; the child's personality attributes (aggression, anxiety, and restlessness); performance on educational tests; and whether they have 
had been in contact with the police by age 16 (see Hobcraft, 1998 for details on the derivation of these variables) .

\subsection{Age at first birth}

We have adopted a simple classification of age at motherhood into those who became mothers as teenagers, when aged 20-22, aged 23-32, and, where relevant, those who had not had a first birth by age 33. These categorisations were adopted after some exploratory work, which suggested that there was not enough information to support a further division of teenage mothers into those aged under 18 and 18-19; equally, there was little evidence that a further sub-division of the older mothers, into age groups 23-26 and 27-32, gave any additional explanatory power to the models. Thus, we consider teenage mothers, early mothers (under age 23), later mothers (23-32), and a no birth by age 33 group.

\subsection{Adult outcomes}

We examine a range of outcomes at age 33 in a number of domains representing different aspects of adult social exclusion, including: welfare, socio-economic, physical health, and emotional well-being, as well as demographic behaviour. The specific outcomes and the percentages of women experiencing each outcome according to the age at which they became mothers are shown in Table 1.

First, we examined two demographic factors: these were whether the woman had ever been a lone-mother by age 33 (19 per cent of all women) and whether her first child was born outside of marriage (12 per cent of all women). These factors, unlike most of the other outcome measures, are not current status variables.

Welfare position was broadly assessed by whether the woman was living in social housing at age 33 (17 per cent of all women) and whether she was in receipt of any non-universal state benefits at age 33 including: income support, family credit, housing benefit, unemployment benefits and one parent family premium (21 per cent of all women).

The socio-economic characteristics considered are whether the women had not attained any qualifications by age 33 (14 per cent of the women had no qualifications) and whether or they were in the lowest quartile of the household income distribution at this age (26 per cent of all women). We also included under this umbrella whether there was a telephone in the household: only 7 per cent of the women fell into this group. Lack of a telephone could be viewed not only as a measure of poverty but also of social isolation. 
Physical health was assessed in two ways. Firstly, a general measure of health was derived from a simple question on "How would you describe your health generally: excellent, good, fair or poor?". This was divided into fair and poor (14 per cent of all women) versus excellent and good. The other physical health measure was whether the woman currently smoked cigarettes (33 per cent of all women did).

\section{Table 1: Proportions of women experiencing each adult outcome by age at first birth (per cent)}

\begin{tabular}{lccccc}
\hline \multirow{2}{*}{ Outcome } & \multicolumn{5}{c}{ Age at first birth } \\
\cline { 2 - 6 } & Under age 20 & $\mathbf{2 0 - 2 2}$ & $\mathbf{2 3 - 3 2}$ & No birth & All women \\
\hline Extra-marital birth & 34.5 & 17.2 & 10.4 & 0.1 & 11.9 \\
Ever lone mother & 53.0 & 34.8 & 13.6 & 0.2 & 18.6 \\
Social housing & 45.2 & 30.8 & 9.7 & 6.2 & 16.9 \\
Any benefits & 43.0 & 33.4 & 17.0 & 8.0 & 20.7 \\
No qualifications & 36.5 & 23.8 & 7.7 & 7.4 & 13.6 \\
Low household income & 43.9 & 32.4 & 20.7 & 25.1 & 26.4 \\
No telephone & 18.2 & 12.2 & 4.2 & 4.2 & 7.2 \\
& & & & & \\
Ill-health & 23.5 & 18.8 & 10.9 & 11.5 & 13.9 \\
Current smoker & 56.4 & 44.3 & 24.7 & 29.2 & 32.8 \\
& & & & & \\
High Malaise & 23.9 & 18.4 & 8.4 & 9.4 & 12.1 \\
Low life satisfaction & 32.3 & 25.9 & 18.0 & 22.2 & 22.0 \\
Number in sample & 664 & 937 & 2689 & 1342 & $5632^{*}$ \\
\hline \hline
\end{tabular}

Note: * Sample sizes vary according to outcome, being especially reduced for the measure of household income

Emotional well-being was also assessed in two ways. The first uses the Malaise Inventory designed by Rutter et al (1970). This is a 24-item list of symptoms such as anxiety, irritability, depressed mood and psychosomatic illness. Scores of seven or more have been used in previous studies to identify those at high risk of depression (Richman, 1978, Rutter et al 1976) and we have subdivided the women into two groups with scores of 7 and above (12 per cent of all women) and those 
with lower scores. The second mental health measure came from responses on a scale from zero to 10 "to show how dissatisfied or satisfied you are about the way your life has turned out so far" with 0 representing completely dissatisfied and 10 completely satisfied. Just over 20 per cent of all women gave responses in the 0-6 range and we refer to this group as those dissatisfied with life.

\section{Tabular analysis}

\subsection{Age at first birth and outcomes}

It is apparent from Table 1 that women who became mothers in their teens had the highest proportions with negative outcomes at age 33 . Across all these domains teenage mothers were more likely than their peers to have these adverse adult experiences. Exploratory analyses showed that the breakdown of age at motherhood used here captures most of the variation in the timing of motherhood with respect to later outcomes. Women who had their child after age 23 were similar in terms of experiencing these outcomes whether they became mothers earlier or later in this age range. We see that across the age groups shown in Table 1 there tends to be a gradient with age at motherhood, in that the sooner women become mothers the more likely are they to have experienced negative outcomes.

\subsection{Poverty in childhood and outcomes}

Our central concern is to try to discover the relative importance of childhood poverty and of early parenthood in relation to the range of adult outcomes considered. As a background to the subsequent multivariate analyses, we commence with an overview and broad description of the bivariate associations of childhood poverty and early parenthood with later outcomes.

Table 2 shows how the timing of motherhood varies with level of poverty experienced during childhood. It is clear from this table that the greater the level of poverty experienced during childhood the more likely was the woman to have become a teenage mother: for example 8 per cent of the girls who did not experience childhood poverty became teenage mothers, compared with 31 per cent of the women who were assessed as clearly poor. Amongst women who had experienced some poverty in childhood (the three top groups) over 45 per cent had had their first child prior to age 23 as compared with 23 per cent of those in the lowest two groups (not or probably not poor). 
Table 2: Percentage distribution of age at first birth amongst women according to level of poverty in childhood

\begin{tabular}{lccccc}
\hline \hline Poverty & $\begin{array}{c}\text { Under } \\
\text { age 20 }\end{array}$ & $\begin{array}{c}\mathbf{2 0 - 2 2} \\
\text { years }\end{array}$ & $\begin{array}{c}\mathbf{2 3 - 3 2} \\
\text { years }\end{array}$ & $\begin{array}{c}\text { No } \\
\text { child }\end{array}$ & $\begin{array}{c}\text { Number in sample } \\
\text { Total=100\% }\end{array}$ \\
\hline Not poor & 7.9 & 14.0 & 52.0 & 26.1 & 2252 \\
Probably not poor & 9.5 & 15.6 & 50.1 & 24.8 & 1955 \\
Some poverty & 18.1 & 21.8 & 40.1 & 20.0 & 639 \\
Fairly poor & 24.3 & 24.3 & 35.8 & 15.7 & 453 \\
Clearly poor & 31.0 & 23.9 & 34.8 & 10.3 & 184 \\
Missing & 12.8 & 14.8 & 38.3 & 34.2 & 149 \\
\hline \hline
\end{tabular}

\subsection{Poverty, age at first birth and outcomes}

In Table 3 we move a stage further and examine the extent to which women experience each outcome according to the level of poverty in childhood and the age at which the women had their first child. A number of general observations emerge from this table.

Table 3: Proportions of women experiencing each outcome according to level of poverty in childhood by age at first birth (per cent)

\begin{tabular}{lccccccc}
\hline \hline Age at first birth & $\begin{array}{c}\text { Extra- } \\
\text { marital } \\
\text { birth }\end{array}$ & $\begin{array}{c}\text { Ever } \\
\text { lone- } \\
\text { mother }\end{array}$ & $\begin{array}{c}\text { Social } \\
\text { housing }\end{array}$ & $\begin{array}{c}\text { Any } \\
\text { benefits }\end{array}$ & $\begin{array}{c}\text { No } \\
\text { qualific- } \\
\text { ations }\end{array}$ & $\begin{array}{c}\text { Low } \\
\text { household } \\
\text { income }\end{array}$ & $\begin{array}{c}\text { No } \\
\text { telephone }\end{array}$ \\
\hline Under age 20 & 27.1 & 50.9 & 38.9 & 38.6 & 29.7 & 35.1 & 13.1 \\
Not poor & 37.3 & 56.6 & 37.9 & 40.4 & 26.9 & 40.9 & 13.7 \\
Probably not poor & 30.2 & 51.7 & 43.4 & 49.1 & 38.4 & 48.8 & 20.2 \\
Some poverty & 39.1 & 49.1 & 58.3 & 42.7 & 45.4 & 43.2 & 25.4 \\
Fairly poor & 43.9 & 54.5 & 67.9 & 57.1 & 68.5 & 70.4 & 31.6 \\
Clearly poor & 47.4 & 63.2 & 38.9 & 31.6 & 35.3 & 45.4 & 15.9 \\
Missing & & & & & & & \\
& & & & & & & \\
20-22 & 12.7 & 30.8 & 23.9 & 29.2 & 16.7 & 28.3 & 6.7 \\
Not poor & 15.4 & 35.8 & 31.2 & 31.6 & 17.9 & 31.6 & 9.9 \\
Probably not poor & 20.8 & 32.6 & 34.1 & 38.2 & 30.9 & 30.0 & 12.9 \\
Some poverty & 27.3 & 41.7 & 40.6 & 43.1 & 41.7 & 44.4 & 27.5 \\
Fairly poor & 20.5 & 43.2 & 51.2 & 40.9 & 41.9 & 51.6 & 25.6 \\
Clearly poor & 27.3 & 40.9 & 18.2 & 27.3 & 38.1 & 18.8 & 18.2 \\
Missing & & & & & & & \\
\hline
\end{tabular}




\begin{tabular}{lccccccc}
\hline 23-32 & & & & & & & \\
Not poor & 7.4 & 11.2 & 6.5 & 13.9 & 3.6 & 17.3 & 2.8 \\
Probably not poor & 10.9 & 13.8 & 8.4 & 17.1 & 5.8 & 19.0 & 3.1 \\
Some poverty & 13.2 & 15.5 & 14.9 & 20.2 & 14.5 & 26.5 & 9.0 \\
Fairly poor & 22.8 & 21.6 & 27.6 & 24.8 & 24.4 & 37.0 & 11.1 \\
Clearly poor & 17.2 & 28.6 & 24.2 & 34.4 & 32.8 & 38.3 & 9.5 \\
Missing & 7.0 & 12.3 & 7.0 & 24.6 & 16.4 & 23.3 & 5.4 \\
& & & & & & & \\
No child & & & & & & & \\
Not poor & 0.0 & 0.0 & 4.0 & 7.0 & 3.8 & 22.6 & 2.6 \\
Probably not poor & 0.0 & 0.0 & 5.8 & 6.8 & 8.3 & 22.2 & 3.8 \\
Some poverty & 0.0 & 0.0 & 11.3 & 11.0 & 9.5 & 35.1 & 6.4 \\
Fairly poor & 0.0 & 0.0 & 16.1 & 15.5 & 18.3 & 41.9 & 8.4 \\
Clearly poor & 0.0 & 0.0 & 6.2 & 15.8 & 21.1 & 37.5 & 15.8 \\
Missing & 0.0 & 0.0 & 6.8 & 9.8 & 16.3 & 24.1 & 9.8 \\
& & & & & & & \\
All women & & & & & & & \\
Not poor & 7.8 & 14.1 & 11.1 & 16.2 & 7.5 & 21.6 & 4.1 \\
Probably not poor & 11.4 & 17.9 & 14.3 & 19.0 & 10.2 & 23.9 & 5.3 \\
Some poverty & 15.5 & 22.9 & 23.6 & 27.5 & 21.3 & 33.0 & 11.3 \\
Fairly poor & 24.3 & 29.7 & 36.8 & 32.2 & 32.7 & 40.9 & 18.2 \\
Clearly poor & 25.0 & 37.6 & 42.9 & 41.0 & 44.4 & 51.4 & 20.9 \\
Missing & 12.8 & 18.8 & 12.8 & 20.8 & 21.8 & 25.2 & 10.1 \\
\hline \hline
\end{tabular}


Table 3 (continued): Proportions of women experiencing poverty in childhood by age at first birth (per cent)

\begin{tabular}{|c|c|c|c|c|}
\hline Age at first birth & Ill-health & $\begin{array}{l}\text { Current } \\
\text { smoker }\end{array}$ & $\begin{array}{l}\text { High malaise } \\
\text { score }\end{array}$ & $\begin{array}{c}\text { Low life } \\
\text { satisfaction }\end{array}$ \\
\hline \multicolumn{5}{|l|}{ Under age 20} \\
\hline Not poor & 18.9 & 51.4 & 19.8 & 28.8 \\
\hline Probably not poor & 25.0 & 56.2 & 18.4 & 29.3 \\
\hline Some poverty & 23.3 & 56.0 & 30.2 & 34.0 \\
\hline Fairly poor & 27.5 & 59.1 & 29.1 & 36.4 \\
\hline Clearly poor & 30.4 & 71.9 & 35.1 & 36.5 \\
\hline Missing & 10.5 & 44.4 & 15.8 & 50.0 \\
\hline \multicolumn{5}{|l|}{$20-22$} \\
\hline Not poor & 16.2 & 38.0 & 16.5 & 26.9 \\
\hline Probably not poor & 14.5 & 43.4 & 12.8 & 24.7 \\
\hline Some poverty & 26.3 & 54.7 & 21.6 & 23.7 \\
\hline Fairly poor & 25.4 & 53.6 & 30.9 & 26.0 \\
\hline Clearly poor & 20.4 & 54.5 & 25.6 & 35.9 \\
\hline Missing & 31.8 & 13.6 & 27.2 & 25.0 \\
\hline \multicolumn{5}{|l|}{$23-32$} \\
\hline Not poor & 9.8 & 21.3 & 6.9 & 15.7 \\
\hline Probably not poor & 9.5 & 23.3 & 8.2 & 18.6 \\
\hline Some poverty & 15.1 & 31.4 & 11.4 & 20.7 \\
\hline Fairly poor & 16.2 & 41.4 & 10.5 & 21.7 \\
\hline Clearly poor & 24.2 & 43.8 & 20.6 & 30.5 \\
\hline Missing & 10.5 & 19.3 & 8.8 & 22.2 \\
\hline \multicolumn{5}{|l|}{ No Child } \\
\hline Not poor & 9.4 & 26.1 & 7.7 & 19.9 \\
\hline Probably not poor & 12.9 & 29.3 & 7.9 & 21.1 \\
\hline Some poverty & 14.4 & 36.7 & 13.4 & 30.1 \\
\hline Fairly poor & 12.7 & 38.0 & 21.1 & 21.2 \\
\hline Clearly poor & 27.8 & 47.4 & 5.6 & 41.2 \\
\hline Missing & 8.0 & 19.3 & 18.0 & 35.4 \\
\hline
\end{tabular}




\begin{tabular}{lcccc}
\hline All women & & & & \\
Not poor & 11.3 & 27.2 & 9.5 & 19.3 \\
Probably not poor & 12.6 & 31.1 & 9.8 & 21.2 \\
Some poverty & 18.9 & 42.0 & 17.4 & 25.6 \\
Fairly poor & 20.7 & 48.1 & 21.6 & 26.1 \\
Clearly poor & 25.6 & 55.4 & 24.9 & 34.7 \\
Missing & 12.8 & 23.6 & 15.5 & 30.7 \\
\hline \hline
\end{tabular}

Initially let us focus on the two extreme groups of the poverty distribution: the "not poor" and the "clearly poor". Across all the outcomes the not poor group of women are more likely to have adverse adult experiences the younger the age at motherhood and the "clearly poor" group have lower probabilities of adverse outcomes the later they become mothers. These relationships are noticeably strong with respect to the demographic behaviours of having a child outside of marriage or becoming a lone parent, as well as with the socio-economic and welfare outcomes, with somewhat weaker relationships for ill-health (but not smoking) and the two emotional well-being measures. The strong relationship with the demographic behaviours is not unexpected given that the extra-marital childbearing is more common for those who enter motherhood early and the chances of becoming a lone-mother reflect higher propensities for early births to occur outside partnerships, for early partnerships to subsequently break down and a longer exposure to risk amongst the younger mothers.

There is also a tendency for the chances of an adverse outcome to be more weakly related to the level of poverty during childhood amongst the teenage mothers than is the case for older mothers, particularly those who delayed having a child to after age 23. Amongst this delayed motherhood group, we see higher proportions experiencing negative outcomes with increasing childhood poverty in most of the domains; but this is the case for a more limited number of domains amongst the teenage mothers. For example, amongst the teenage mothers the proportions who have ever been lone parents are invariant with childhood poverty, and there is only a weak association with smoking and life-satisfaction, but there is an increasing association with level of childhood poverty for social housing and having no qualifications. These findings suggest that degree of childhood poverty may be a more important discriminator at older ages of motherhood in affecting how these mothers lives subsequently unfold but that becoming a teenage mother regardless of degree of childhood poverty 
has a more general negative impact on subsequent life experiences. Our multivariate analyses will address and assess these issues more rigorously.

\section{Does age at motherhood affect adverse adult outcomes?}

One of our main aims was to test the hypothesis as to whether age at motherhood has a significant association with adverse adult outcomes at age 33 over and above the impact of childhood poverty, as well as a wide range of other childhood background factors. In order to assess this we tried a range of different regression models, each designed with a particular idea in mind, as portrayed in Figure 1.

\subsection{A conceptualisation of the issues}

These concerns are illustrated in their essence in the top left-hand panel of Figure 1. In this diagram, there is a solid line connecting the pathway from childhood poverty to adult outcomes. The most naïve model would see the 'effects' of childhood poverty on the various adult outcomes that we consider as working along this pathway, without any other controls (we refer to this as Model 1). We can then pose the question as to whether introduction of additional controls for age at first birth (termed Model 1A) add any explanatory power to this simple account - in other words, do the dashed lines indicate significant relationships? If they do, we can then examine the extent of the relationships and their magnitude.

A second way of conceptualising the question is shown in the upper right-hand portion of Figure 1. We now recognise that there are a range of other factors reflecting childhood experiences which are themselves likely to be inter-related with childhood poverty, with early parenthood, and with subsequent adult outcomes. But we here give childhood poverty pride of place among the childhood factors, because it is a focus of special interest. We thus insist that childhood poverty levels are included in our Model 2 ('poverty forced'), but pose the question (through a step-wise regression procedure) as to whether and how many of the other childhood factors are relevant to each adult outcome in turn (so that we choose a different Model 2 for every adult outcome). Once we have chosen the appropriate Model 2 for each outcome, we then pose the question as to whether the addition of terms for age at first birth add explanatory power (in Model 2A), whilst 


\section{Figure 1: A Range of Models Designed to Test Whether Early Parenthood Affects Outcomes in Adulthood}

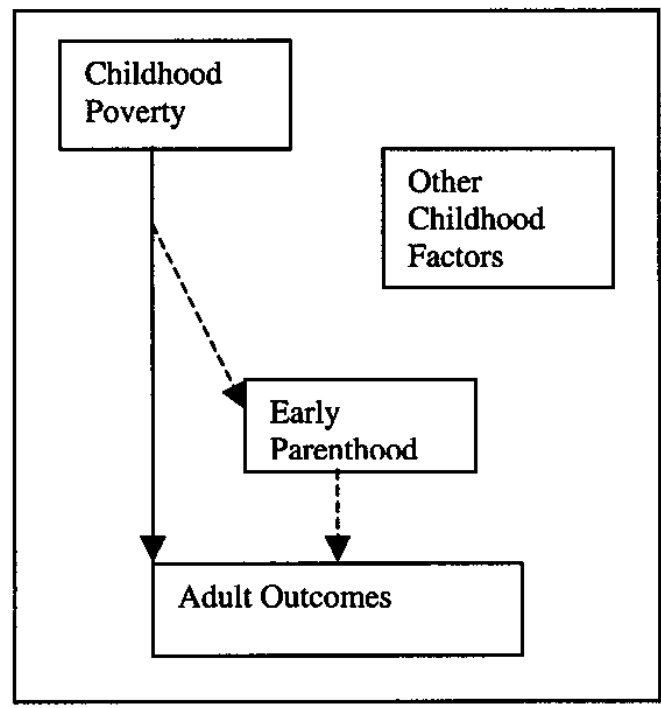

Model 1: Poverty forced

Model 1A: Model 1 forced and Early parenthood tested

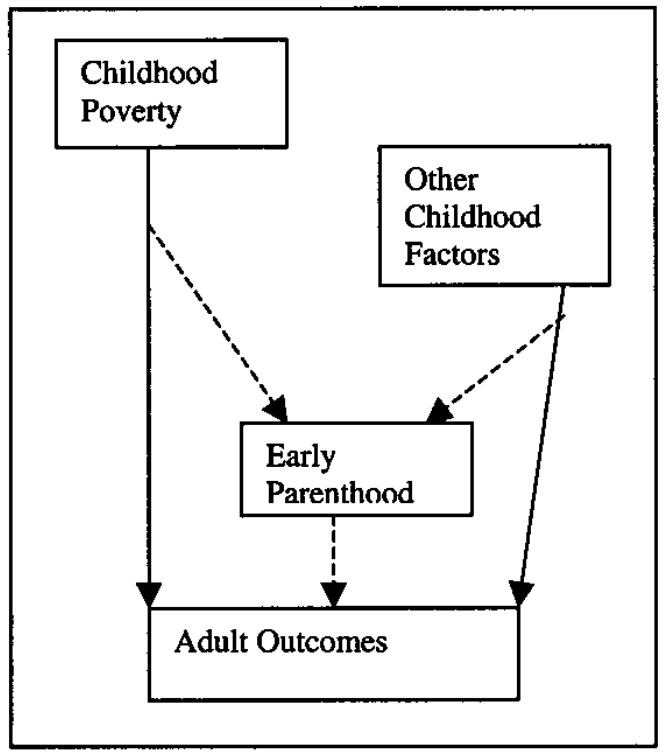

Model 3: Best Poverty and child (no forcing) Model 3A: Model 3 forced and early parenthood tested

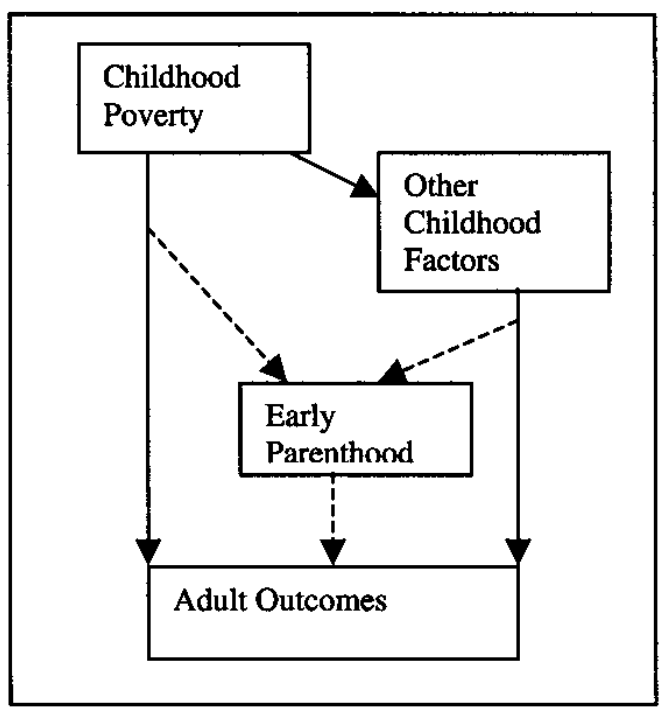

Model 2: Poverty forced; best child addition Model 2A: Model 2 forced and early parenthood tested

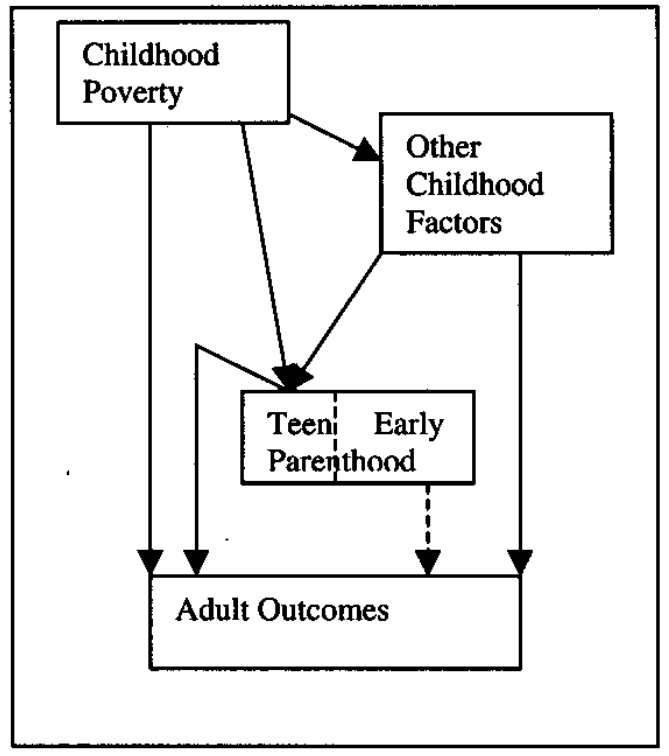

Preliminary model of teenage parenthood: Poverty forced and best child

Model 4: Preliminary model forced and best child on Outcome

Model 4A: Model 4 forced and early parenthood tested 
keeping all of the elements of the relevant Model 2 ('Model 2 forced'). Once again, the pathways included in Model 2 are shown as solid lines and the possible additional pathways for Model 2A are shown as dashed lines. Do the dashed lines in this panel represent significant relationships? If they do, the magnitude of the pathway from early parenthood to the adult outcomes and the magnitudes of the pathways from childhood poverty to adult outcomes, both before and after controlling for age at first birth are of interest.

An alternative conceptualisation would place childhood poverty and the other childhood factors on an equal footing and simply ask which of these childhood precursors were significantly related to each adult outcome in turn (Model 3 - lower left-hand panel of Figure 1). Of particular interest would still be the size of the relationships for childhood poverty. Once Model 3 has been chosen for each outcome, the elements of that model are again 'forced' into Model 3A, to which is added any significant relationships with categories of age at first birth (again effectively capturing the pathways indicated by the dashed lines).

The final, and most elaborate, conceptualisation is illustrated in the lower right-hand panel of Figure 1. This begins by examining a preliminary model (essentially Model 2) for teenage motherhood as a post-childhood outcome, with childhood poverty levels being forced into the model and relevant other childhood factors selected for inclusion. The terms of this preliminary model are then 'forced' into later models, with the object of trying to ensure the models capture the maximum possible explanatory power for teenage motherhood, thus trying to make the final test for inclusion of age at first birth 'effects' (over and above childhood precursors) as stringent as possible. Model 4 is then derived for each outcome in turn, by asking which other childhood factors add explanatory power (over and above childhood poverty and the other childhood factors that are already included in the preliminary model). We can then again pose the question as to whether moving from Model 4 for each outcome to Model 4A adds further explanatory power - are there additional age at first birth effects?

\subsection{Testing the hypothesis of first birth effects}

The first model we considered is shown as Models 1 and 1A in Figure 1. This is the simplest model considered and is quite close to summarising the information shown in Table 3. Model 1 simply includes the levels of childhood poverty in a logistic regression for each of the 11 adverse outcomes in turn. Model 1A retains all of the terms for the levels of childhood poverty (these are forced into the model) and asks whether 
any (or all) of the age at first birth groups show significant differences on each of the adult outcomes, using a forward stepwise inclusion procedure. Given the very simple nature of this model and what we know from the bivariate description it is hardly surprising that age at first birth effects are highly statistically significant and that, for most adult outcomes, all are included. Table 4 shows the likelihood ratio chisquared statistics for the difference in goodness of fit between Models 1 and $1 \mathrm{~A}$ and the related degrees of freedom. The least significant of these additions, a chi-squared of 53 on 3 degrees of freedom, has $p<2 * 10^{-11}$.

Table 4: Increases in likelihood ratio chi-squared statistics with addition of age at first birth to various stepwise logistic models designed to capture effects of childhood poverty and age at first birth

\begin{tabular}{lcccccccc}
\hline \hline Adult outcome & $\begin{array}{c}\text { Model 1 to } \\
\text { Model 1A }\end{array}$ & \multicolumn{2}{c}{$\begin{array}{c}\text { Model 2 to } \\
\text { Model 2A }\end{array}$} & \multicolumn{2}{c}{$\begin{array}{c}\text { Model 3 to } \\
\text { Model 3A }\end{array}$} & \multicolumn{2}{c}{$\begin{array}{c}\text { Model 4 to } \\
\text { Model 4A }\end{array}$} \\
\cline { 2 - 7 } & Chi-sq & df & Chi-sq & df & Chi-sq & df & Chi-sq & df \\
\hline Extra-marital birth & 285 & 2 & 179 & 2 & 181 & 2 & 182 & 2 \\
Ever lone parent & 721 & 2 & 533 & 2 & 535 & 2 & 535 & 2 \\
& & & & & & & & \\
Social housing & 485 & 3 & 253 & 3 & 253 & 3 & 247 & 3 \\
Any benefit & 362 & 3 & 216 & 3 & 217 & 3 & 215 & 3 \\
& & & & & & & & \\
No qualifications & 290 & 2 & 78 & 2 & 80 & 2 & 78 & 2 \\
Low household income & 77 & 3 & 31 & 3 & 38 & 3 & 34 & 3 \\
No telephone & 117 & 2 & 47 & 1 & 48 & 1 & 45 & 1 \\
& & & & & & & & \\
Ill-health & 60 & 1 & 16 & 1 & 16 & 1 & 15 & 1 \\
Current smoker & 232 & 3 & 109 & 3 & 109 & 3 & 110 & 3 \\
& & & & & & & & \\
Malaise & 106 & 2 & 46 & 1 & 45 & 1 & 44 & 1 \\
Life unsatisfactory & 53 & 3 & 25 & 2 & 26 & 2 & 24 & 2 \\
\hline \hline
\end{tabular}

But Models 1 and 1A hardly comprise a rigorous basis for testing whether age at motherhood is associated with adverse adult outcomes, net of childhood background. In order to assess this further, we considered several alternative models, which included other childhood background factors in different ways. The factors included summarised experience through childhood, where they proved significant in 
stepwise forward models, and were to recap: family type, contact with the police by age 16, grandfathers' and father's social class at birth, and father's social class during the survey member's childhood, housing tenure during childhood, mother's and father's terminal age of education, mother's and father's interest in schooling, results of test scores, and three behavioural indicators (aggression, anxiety, and restlessness).

Model 2 (shown in Figure 1) forces inclusion of childhood poverty, as a variable of focal interest, and then selects the other childhood factors which were statistically significant using a stepwise forward inclusion procedure. All the elements of Model 2 are then forced into a further logistic regression model and the age at first birth effects are added using a stepwise forward selection procedure to provide Model 2A. Again, the improvement in fit of Model 2A, compared with Model 2, is shown in terms of the differences between the relevant likelihoodratio chi-squared statistics in Table 4. Although the measures of improvement in fit have attenuated, compared with Models 1 and 1A, the age at first motherhood elements are still highly statistically significant, with that for poor or fair health having $\mathrm{p}=0.00006$ and all others having even smaller p-values.

A more parsimonious version of model 2 was usually found if the childhood poverty categories were not all forced into the model. Thus, Model 3 permits the stepwise forward selection procedure to choose freely among all childhood factors. The elements of Model 3 are then forced into a further logistic regression (Model 3A) and the inclusion of the age at first birth effects is again tested using a stepwise forward inclusion procedure. The results of comparing Models 3 and 3A are also shown in Table 4 and are virtually identical to those obtained for Models 2 and $2 \mathrm{~A}$.

Our final, and most elaborate, model to test for significant effects of early parenthood on adverse adult outcomes net of childhood background was derived to try to ensure greater potential control for the childhood determinants of teenage motherhood. This began by fitting a preliminary model, which forced the inclusion of the childhood poverty categories and then chose all other significant childhood correlates of teenage motherhood. The elements of this model of teenage motherhood were then forced into Model 4 and any further significant childhood correlates of each adult outcome were also added through a stepwise forward selection procedure. All elements of Model 4 were then forced into a further logistic regression which tested for the addition of the age at first birth effects (Model 4A). Once again, we show comparisons of the 
additional explanatory power of Model 4A compared with Model 4 in Table 4. Despite Model 4 containing many more parameters than the earlier models (though with little, if any, significant improvement in overall fit), the results are again virtually identical to those from comparing Models 2 and 2A or Models 3 and 3A. For every adult outcome, there remains a strongly significant association of the age at first birth net of the childhood controls; moreover, the estimated parameters for these associations were also remarkably robust to the differing specifications, ranging from the parsimonious approach of Model 3 through to the much more elaborate approach of Model 4.

In view of this, here we shall only consider in detail the odds ratios from one of the pairs of models used to assess the net effects of age at first birth after controls for a wide range of childhood background factors, including experience of childhood poverty. The models we have chosen to examine in more detail are Models 3 and 3A, since these are parsimonious (containing fewest parameters) and lead to very similar conclusions to the more complex, but generally no better fitting, models - whilst allowing some noise and over-control is arguably desirable for a rigorous test of the need to include age at first birth effects, models containing several insignificant parameters are much more problematic for interpretation of the results.

\section{Consequences of early motherhood and childhood poverty}

Having demonstrated that highly significant associations of age at first birth with a wide range of adverse adult outcomes still persist after control for a multitude of childhood background factors, we now turn to an examination of the magnitude of the net effects of age at first birth and of levels of childhood poverty on each adult outcome, after controls for the other childhood factors.

The models were fitted using a series of contrasts of entry into motherhood below a particular age, specifically before age 33, before age 23, and before age 20; these are termed 'hierarchical' odds ratios, because the successive restrictions of ages at childbearing form a hierarchy. The levels of childhood poverty were contrasted in a similar hierarchical way. The levels of childhood poverty were contrasted in a similar hierarchical way; not poor, any poverty or probably not poor, any poverty, fairly or clearly poor, and clearly poor. 
The actual estimates of the odds ratios and the associated z-scores for age at first birth are shown in Table 6 and those for childhood poverty in Tables $8 \mathrm{~A}$ and $\mathrm{B}$. These estimated hierarchical odds ratios were then multiplied together to provide the estimated odds ratios which are shown in Table 5 for age at first birth and Table 7 for childhood poverty. With respect to age at first birth there was a further modification that age at birth 23-32 was set as the reference group, with a base odds ratio of one. For example, the odd ratio for the risk of having an extra-marital birth for a teenage mother of 4.51:1 (in Table 5) is derived by multiplying the odds for having a birth before age 23 (2.17:1, from Table 6) by the additional odds ratio for having a birth before age 20 (2.08:1, from Table 6).

\subsection{Consequences of age at first birth}

We begin by examining the estimated odds ratios for age at first birth. The most dramatic contrasts in adult outcomes arise from comparing all those women who had their first birth before age 23 with those who first became mothers between ages 23 and 32 years (most clearly seen from Table 6, where the hierarchical odds ratios are frequently largest for this contrast). These differences are often, but not always, further reinforced when the early birth occurred during the woman's teens, as shown in Table 6. In view of this, we begin by looking at the odds ratios for early motherhood (before age 23).

Early mothers (under age 23) are (see Table 5 or 6):

$>4.4$ times as likely to have ever been a lone parent by age 33;

$>\quad$ about 3 times more likely to be resident in social housing at age 33;

$>\quad$ about twice as likely to have had an extra-marital birth, to be in receipt of non-universal benefits at age 33, to have no qualifications at age 33, to not have a telephone in their household at age 33 , to be a cigarette smoker at age 33 , and to experience a high malaise score at age 33;

$>\quad$ and about 40 per cent more likely to have a low household income at age 33 , to report general poor or fair health at age 33 , and to rate life as unsatisfactory.

For teenage mothers, these effects are often higher still (compared with early mothers in their twenties), being further (see Table 6):

$>$ about doubled for extra-marital births, and experience of lone parenthood;

$>\quad$ increased by about $50 \%$ for social housing;

$>\quad$ up by about another $40 \%$ for benefit receipt, lack of qualifications, and low household income; 
$>\quad$ and up by another $30 \%$ for smoking.

But there is no additional impact of a teenage birth (compared with one in the early 20s) on lack of access to a telephone, general ill health, malaise, or life dissatisfaction.

Teenage mothers consequently have odds of adverse adult outcomes (compared with those who first become mothers at ages 23-32) of (see Table 5):

$>\quad$ over 8:1 of having experienced lone parenthood by age 33;

$>\quad$ over 4:1 of having had an extra-marital birth and of being in social housing at age 33;

$>\quad$ about 2.5:1 of being in receipt of non-universal benefits at age 33 (over 13 years after the first birth), and of having no qualifications, and being current cigarette smokers at age 33;

$>\quad$ about 2:1 of not having a telephone, being in a low income household, and experiencing malaise at age 33;

$>\quad$ and about $1.5: 1$ of saying life is unsatisfactory, and of reporting their general health as poor or fair.

We also see in Table 5 that women who had not had a birth by age 32 were: the least likely to be in social housing or in receipt of nonuniversal benefits; as likely as those who had a first birth between ages 23 and 32 (and thus jointly least likely) to have no qualifications, to not have access to a telephone, to report poor or fair general health, and to experience malaise; but were more likely than those who had a birth between age 23 and 32 to have low household income, to smoke cigarettes, and to be dissatisfied with their lives; and, of course, lone parenthood and extra-marital births are not relevant outcomes for those who have not yet had a birth.

We emphasise that care must be taken in interpreting these odds ratios by age at entry into motherhood too literally as being an 'effect' of age at first birth. These odds ratios remain statistically significant in the face of a wide range of controls for childhood background factors and thus address the question as to whether there are 'effects' of age at first birth net of these controls. But it must be stressed that no other factors in adulthood are included in the models, so that we are not trying to 'explain' how these often strong associations of adverse adult outcomes with age at first birth arise. It is entirely plausible, and indeed probable, that early motherhood is fairly directly linked with reducing choices and opportunities in ways that have profound and lasting effects, but there are of course likely to be other factors associated with early motherhood which partly determine adverse outcomes later in life. 
Table 5: Odds ratios for experiencing adult outcomes by age at first birth, net of childhood poverty and other childhood controls (Model 3A)

\begin{tabular}{lcccc}
\hline \hline & \multicolumn{4}{c}{ Age at first birth } \\
\cline { 2 - 5 } Adult outcome & Teenage & $\mathbf{2 0 - 2 2}$ & $\mathbf{2 3 - 3 2}$ & No birth \\
\hline Extra-marital birth & 4.51 & 2.17 & 1.00 & \\
Ever lone parent & 8.32 & 4.43 & 1.00 & \\
& & & & \\
Social housing & 4.28 & 2.89 & 1.00 & 0.74 \\
Any benefits & 2.42 & 1.90 & 1.00 & 0.45 \\
& & & & \\
No qualifications & 2.73 & 1.99 & 1.00 & 1.00 \\
Low household income & 1.92 & 1.39 & 1.00 & 1.45 \\
No telephone & 2.21 & 2.21 & 1.00 & 1.00 \\
& & & & \\
General ill-health & 1.42 & 1.42 & 1.00 & 1.00 \\
Current smoker & 2.45 & 1.86 & 1.00 & 1.40 \\
& & & & \\
Malaise & 1.86 & 1.86 & 1.00 & 1.00 \\
Life unsatisfactory & 1.46 & 1.46 & 1.00 & 1.34 \\
\hline \hline
\end{tabular}


Table 6: Hierarchical odds ratios (and related z-scores) of experiencing adult outcomes for age at first birth, net of childhood poverty and other childhood controls (Model 3A)

\begin{tabular}{lcccccccc}
\hline \hline & \multicolumn{7}{c}{ Age at first birth } \\
\cline { 2 - 8 } & \multicolumn{1}{c}{ Before age 20 } & \multicolumn{2}{c}{ Before age 22 } & Before age 32 & $\begin{array}{c}\text { No } \\
\text { birth }\end{array}$ \\
& $\begin{array}{l}\text { Odds } \\
\text { ratio }\end{array}$ & z-score & $\begin{array}{c}\text { Odds } \\
\text { ratio }\end{array}$ & z-score & $\begin{array}{c}\text { Odds } \\
\text { ratio }\end{array}$ & $\begin{array}{c}\text { z-score } \\
\text { Odds } \\
\text { ratio }\end{array}$ \\
\hline Extra-marital birth & 2.08 & $(5.9)$ & 2.17 & $(6.9)$ & 1.00 & --- \\
Ever lone parent & 1.88 & $(5.9)$ & 4.43 & $(16.2)$ & 1.00 & --- \\
Social housing & 1.48 & $(3.4)$ & 2.89 & $(10.2)$ & 1.35 & $(2.1)$ & 1.00 \\
Any benefits & 1.27 & $(2.2)$ & 1.90 & $(7.1)$ & 2.23 & $(7.0)$ & 1.00 \\
No qualifications & 1.38 & $(2.4)$ & 1.99 & $(6.0)$ & 1.00 & & 1.00 \\
Low household incomenyyyyyyyyyy & 1.38 & $(2.4)$ & 1.39 & $(3.1)$ & 0.69 & $(-3.7)$ & 1.00 \\
No telephone & 1.00 & & 2.21 & $(6.9)$ & 1.00 & & 1.00 \\
General ill-health & 1.00 & & 1.42 & $(4.0)$ & 1.00 & & 1.00 \\
Current smoker & 1.32 & $(2.6)$ & 1.86 & $(7.4)$ & 0.72 & $(-4.3)$ & 1.00 \\
Malaise & 1.00 & & 1.86 & $(6.8)$ & 1.00 & & 1.00 \\
Life unsatisfactory & 1.00 & & 1.46 & $(4.7)$ & 0.74 & $(-3.5)$ & 1.00 \\
\hline \hline
\end{tabular}

\subsection{Consequences of levels of childhood poverty}

We now turn to an examination of the associations of levels of childhood poverty with the adult outcomes. Childhood poverty is evidently associated with the propensity to have an early first birth, as shown descriptively without other childhood controls in our earlier analysis of Table 3 and more rigorously in our earlier work on teenage motherhood Kiernan (1997) and Hobcraft (1998). In view of this association, we examine the odds ratios from both Model 3, which includes poverty and other childhood controls, and Model 3A, which further controls for age at first motherhood (Figure 1). The estimates for these pairs of odds ratios are shown in Table 7 . The related 'hierarchical' odds ratios and the supporting z-scores are shown in Tables 8A (for Model 3) and 8B (for Model 3A). For each adult outcome shown in Table 7, the first set of odds ratios are net of other childhood factors (we do not show the 'gross' odds ratios from Model 1, because at least some of the other 
childhood factors are as likely to be causes of childhood poverty as effects). The second set of odds ratios for each adult outcome are net of both the other childhood factors and the age at first birth, thus showing the extent to which these associations are captured by the inclusion of age at first birth, which is itself related to childhood poverty (in essence, any experience of childhood poverty increases the odds of a teenage birth to 1.6:1 and the odds of a birth under age 23 to 1.45:1).

From Table 7 (and even more clearly from Tables $8 \mathrm{~A}$ and $8 \mathrm{~B}$ ) it is evident that the biggest 'divide' in the odds ratios for adult outcomes occurs with any evidence of childhood poverty: the hierarchical odds ratios for this group are statistically significant for every outcome except dissatisfaction with life in Model 3 and only become insignificant in Model 3A for lone parenthood. There is no evidence to suggest that the group who were 'probably not poor' during childhood experience differences in any of the adult outcomes (see Tables 8A and 8B). Where no information was available on childhood poverty at any of the childhood waves of NCDS (All missing), there is no statistically significant relationship with any of the adverse outcomes, except dissatisfaction with life at age 33. Moreover, there are only very few indications of any reinforcement of the effects of any experience of childhood poverty by greater intensity of such poverty: having been clearly or fairly poor during childhood further increases the odds of being in social housing at age 33; and having been clearly poor during childhood is associated with a further increase in the odds of having no qualifications, of having a low household income, and of reporting low levels of satisfaction with life, all at age 33 . 
Table 7: Odds ratios for experiencing adult outcomes by level of childhood poverty, net of other childhood factors (Model 3) and net of other childhood factors and age at first birth (Model 3A)

\begin{tabular}{|c|c|c|c|c|c|c|c|}
\hline \multirow[b]{2}{*}{ Adult outcome } & & \multicolumn{6}{|c|}{ Childhood poverty status } \\
\hline & & Not poor & $\begin{array}{l}\text { Probably } \\
\text { not poor }\end{array}$ & $\begin{array}{c}\text { Some } \\
\text { poverty }\end{array}$ & $\begin{array}{l}\text { Fairly } \\
\text { poor }\end{array}$ & $\begin{array}{c}\text { Clearly } \\
\text { poor }\end{array}$ & $\underset{\text { missing }}{\text { All }}$ \\
\hline \multirow[t]{2}{*}{ Extra-marital birth } & Net child & 1.00 & 1.00 & 1.49 & 1.49 & 1.49 & 1.00 \\
\hline & Net both & 1.00 & 1.00 & 1.30 & 1.30 & 1.30 & 1.00 \\
\hline \multirow[t]{2}{*}{ Ever lone parent } & Net child & 1.00 & 1.00 & 1.31 & 1.31 & 1.31 & 1.00 \\
\hline & Net both & 1.00 & 1.00 & 1.06 & 1.06 & 1.06 & 1.00 \\
\hline \multirow[t]{2}{*}{ Social housing } & Net child & 1.00 & 1.00 & 1.37 & 2.00 & 2.00 & 1.00 \\
\hline & Net both & 1.00 & 1.00 & 1.27 & 1.80 & 1.80 & 1.00 \\
\hline \multirow[t]{2}{*}{ Any benefits } & Net child & 1.00 & 1.00 & 1.40 & 1.40 & 1.40 & 1.00 \\
\hline & Net both & 1.00 & 1.00 & 1.27 & 1.27 & 1.27 & 1.00 \\
\hline \multirow[t]{2}{*}{ No qualifications } & Net child & 1.00 & 1.00 & 1.66 & 1.66 & 2.52 & 1.00 \\
\hline & Net both & 1.00 & 1.00 & 1.52 & 1.52 & 2.31 & 1.00 \\
\hline \multirow{2}{*}{$\begin{array}{l}\text { Low household } \\
\text { income }\end{array}$} & Net child & 1.00 & 1.00 & 1.40 & 1.40 & 2.11 & 1.00 \\
\hline & Net both & 1.00 & 1.00 & 1.35 & 1.35 & 1.98 & 1.00 \\
\hline \multirow[t]{2}{*}{ No telephone } & Net child & 1.00 & 1.00 & 1.97 & 1.97 & 1.97 & 1.00 \\
\hline & Net both & 1.00 & 1.00 & 1.83 & 1.83 & 1.83 & 1.00 \\
\hline \multirow[t]{2}{*}{ General ill-health } & Net child & 1.00 & 1.00 & 1.23 & 1.23 & 1.23 & 1.00 \\
\hline & Net both & 1.00 & 1.00 & 1.23 & 1.23 & 1.23 & 1.00 \\
\hline \multirow[t]{2}{*}{ Current smoker } & Net child & 1.00 & 1.00 & 1.33 & 1.33 & 1.33 & 1.00 \\
\hline & Net both & 1.00 & 1.00 & 1.25 & 1.25 & 1.25 & 1.00 \\
\hline \multirow[t]{2}{*}{ Malaise } & Net child & 1.00 & 1.00 & 1.53 & 1.53 & 1.53 & 1.00 \\
\hline & Net both & 1.00 & 1.00 & 1.43 & 1.43 & 1.43 & 1.00 \\
\hline \multirow[t]{2}{*}{ Life unsatisfactory } & Net child & 1.00 & 1.00 & 1.00 & 1.00 & 1.42 & 1.70 \\
\hline & Net both & 1.00 & 1.00 & 1.00 & 1.00 & 1.39 & 1.65 \\
\hline
\end{tabular}


Table 8A: Hierarchical odds ratios of experiencing adult outcomes by level of childhood poverty, net of other childhood controls (Model 3)

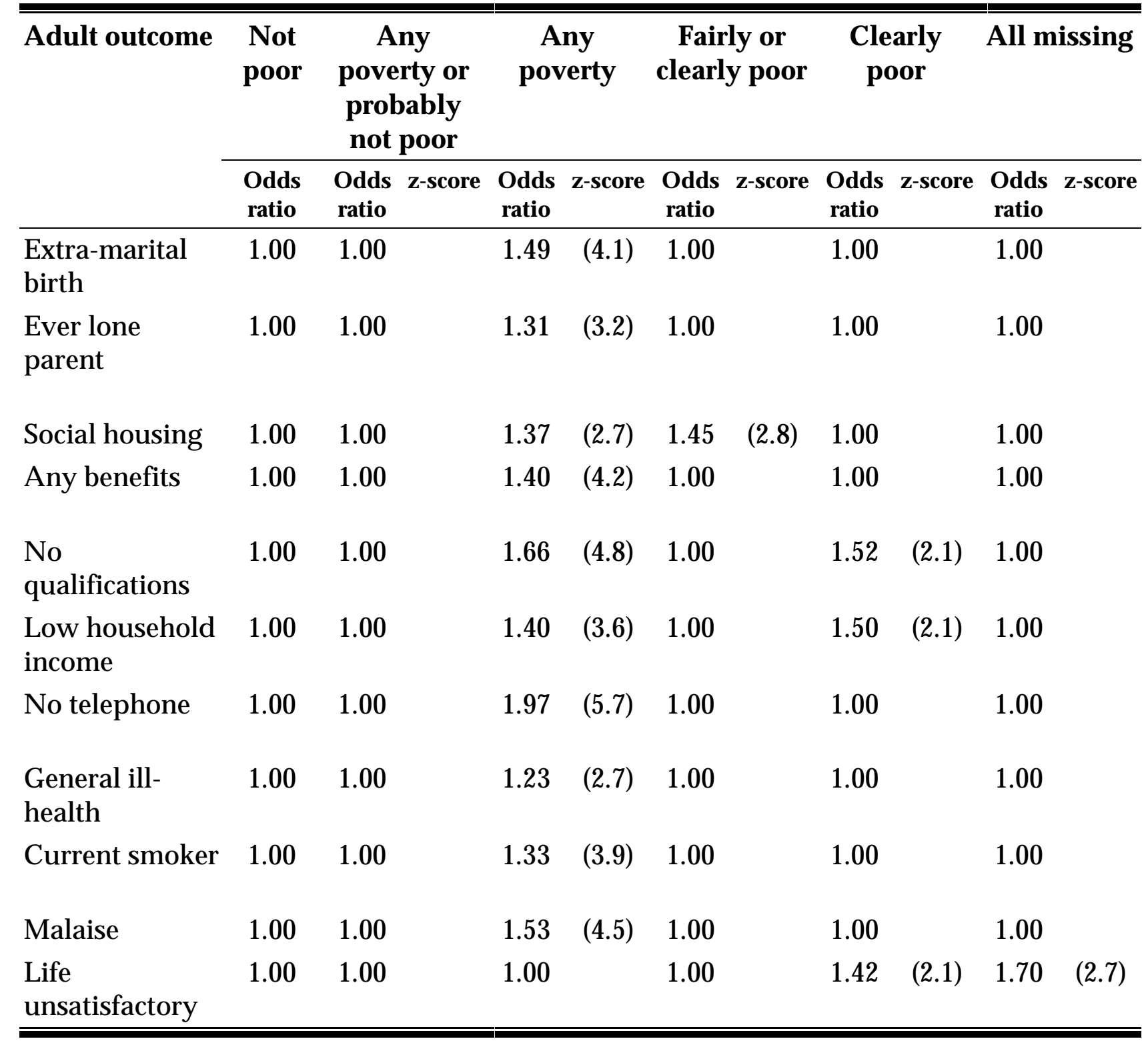


Table 8B: Hierarchical odds ratios (and related z-scores) of experiencing adult outcomes for level of childhood poverty, net of other childhood controls and age at first birth (Model 3A)

\begin{tabular}{|c|c|c|c|c|c|c|c|c|c|c|}
\hline \multirow{3}{*}{ Adult outcome } & \multicolumn{10}{|c|}{ Level of childhood poverty } \\
\hline & \multirow{2}{*}{$\begin{array}{l}\begin{array}{c}\text { Not } \\
\text { poor }\end{array} \\
\begin{array}{c}\text { Odds } \\
\text { ratio }\end{array}\end{array}$} & $\begin{array}{l}\text { Any } \\
\text { poverty or } \\
\text { probably } \\
\text { not poor }\end{array}$ & \multicolumn{2}{|c|}{ Any poverty } & \multicolumn{2}{|c|}{$\begin{array}{l}\text { Fairly or } \\
\text { clearly poor }\end{array}$} & \multicolumn{2}{|c|}{$\begin{array}{l}\text { Clearly } \\
\text { poor }\end{array}$} & \multicolumn{2}{|c|}{ All missing } \\
\hline & & $\begin{array}{l}\text { Odds } z \text {-score } \\
\text { ratio }\end{array}$ & $\begin{array}{l}\text { Odds } \\
\text { ratio }\end{array}$ & z-score & $\begin{array}{l}\text { Odds } \\
\text { ratio }\end{array}$ & z-score & $\begin{array}{l}\text { Odds } \\
\text { ratio }\end{array}$ & z-score & $\begin{array}{l}\text { Odds } \\
\text { ratio }\end{array}$ & z-score \\
\hline $\begin{array}{l}\text { Extra-marital } \\
\text { birth }\end{array}$ & 1.00 & 1.00 & 1.30 & $(2.6)$ & 1.00 & & 1.00 & & 1.00 & \\
\hline Ever lone parent & 1.00 & 1.00 & 1.06 & $(0.7)$ & 1.00 & & 1.00 & & 1.00 & \\
\hline Social housing & 1.00 & 1.00 & 1.27 & $(2.0)$ & 1.42 & $(2.5)$ & 1.00 & & 1.00 & \\
\hline Any benefits & 1.00 & 1.00 & 1.27 & $(2.9)$ & 1.00 & & 1.00 & & 1.00 & \\
\hline $\begin{array}{l}\text { No } \\
\text { qualifications }\end{array}$ & 1.00 & 1.00 & 1.52 & $(3.9)$ & 1.00 & & 1.52 & $(2.1)$ & 1.00 & \\
\hline $\begin{array}{l}\text { Low household } \\
\text { income }\end{array}$ & 1.00 & 1.00 & 1.35 & $(3.1)$ & 1.00 & & 1.47 & $(2.0)$ & 1.00 & \\
\hline No telephone & 1.00 & 1.00 & 1.83 & $(5.1)$ & 1.00 & & 1.00 & & 1.00 & \\
\hline $\begin{array}{l}\text { General ill- } \\
\text { health }\end{array}$ & 1.00 & 1.00 & 1.23 & $(2.3)$ & 1.00 & & 1.00 & & 1.00 & \\
\hline Current smoker & 1.00 & 1.00 & 1.25 & $(3.0)$ & 1.00 & & 1.00 & & 1.00 & \\
\hline Malaise & 1.00 & 1.00 & 1.43 & $(3.8)$ & 1.00 & & 1.00 & & 1.00 & \\
\hline $\begin{array}{l}\text { Life } \\
\text { unsatisfactory }\end{array}$ & 1.00 & 1.00 & 1.00 & & 1.00 & & 1.39 & (1.9) & 1.65 & $(2.6)$ \\
\hline
\end{tabular}

In view of the clear divide associated with any experience of childhood poverty whatsoever, we begin by examining the odds ratios for that group. The 'total' effects of any childhood poverty (net of other childhood factors, but not of age at first birth) on adult outcomes are not generally as large as those for the other 'great divide' of an early first birth, but are nevertheless generally significant (Table 8A):

$>$ twice the risk of not having a telephone in the household;

$>\quad$ two-thirds more likely to have no qualifications at age 33; 
$>$ about $50 \%$ more likely to have had an extra-marital birth, or to have high malaise score;

$>$ about $40 \%$ more likely to be resident in social housing, to be in receipt of non-universal benefits, and to have a low household income;

$>\quad$ a third more likely to be a cigarette smoker at age 33;

$>\quad$ and a quarter more likely to report general poor or fair health at 33.

Once the additional controls for age at first birth are introduced these odds ratios are usually attenuated further, though the reductions are often quite small (see Table 7). Only the association with experience of lone parenthood with childhood poverty becomes statistically insignificant (along with the life dissatisfaction, where the 'total' effect was already not significant). The generally partial attenuation indicates that little of the childhood poverty association operates through age at first birth, but rather remains as a direct effect on the adult outcomes. Once age at first birth has been controlled, these residual 'direct' effects of any experience of childhood poverty are(Table 8B):

$>\quad$ an $83 \%$ excess risk of not having a telephone in the household at age 33;

$>50 \%$ more likely to have no qualifications at age 33;

$>\quad$ about $40 \%$ more likely to experience malaise at age 33;

$>$ roughly one-third more likely to have had an extra-marital birth, and to have low household income;

about one-quarter more likely to be in social housing, to be in receipt of non-universal benefits, to be a cigarette smoker, and to report poor or fair general health at age 33.

The few additional associations with more intense levels of childhood poverty, being fairly and clearly poor, further increase the likelihood of (Table 7):

$>\quad$ being in social housing at age 33 to a doubling for the 'total' effect of having been fairly or clearly poor as a child, and $80 \%$ excess for the net effect;

$>\quad$ having no qualifications at age 33 to two and a half times for the 'total' effect of having been clearly poor during childhood, and 2.3 times for the net effect;

$>\quad$ having a low household income at age 33 to about double for both the total and net effects of having been clearly poor during childhood;

and produce an odds ratio of borderline statistical significance (at the $5 \%$ level) of about 1.4:1 (total and net) of those who were 
clearly poor during childhood reporting low levels of satisfaction with their lives; in addition, the lack of any information on childhood poverty is associated with about a two-thirds increase in the odds of life dissatisfaction at age 33.

\subsection{Joint effects of age at first birth and childhood poverty}

We have also explored the extent of interaction between childhood poverty and early childbearing (under age 23) as co-associates of the adult outcomes, by looking at combinations of early childbearing with any childhood poverty and of teenage motherhood with any childhood poverty. These interactions only proved to add significant explanatory power for three of the adult outcomes: having had an extra-marital birth, ever having been a lone parent, and living in social housing at age 33.

For extra-marital births, the significant interaction proved to be between teenage motherhood and any childhood poverty and the conclusion to be drawn from that model (not shown) is that all teenage mothers, regardless of their level of childhood poverty, show about the same (five-fold) excess odds of having had an extra-marital birth, but that the odds of having an extra-marital birth were increased by an extra $55 \%$ for those who experienced any childhood poverty among women who became mothers at ages 20-22 (roughly from two to three) or 23-32 (from one to 1.55).

For lone parenthood, the significant interaction appeared to be the combination of early motherhood with any experience of childhood poverty and again this strongly suggested that lone parenthood for those who become mothers early is unrelated to childhood poverty levels, being an odds ratio of about nine to one for teenage mothers and of just under five to one for those who became mothers in their early twenties. But the odds ratio of experiencing lone parenthood for those who had their first birth between ages 23 and 32 was $40 \%$ higher for those who had any childhood poverty (at 1.40).

In the case of social housing, the significant interaction was again of early motherhood with any childhood poverty. Because of the additional effect for higher levels of childhood poverty, the picture is a little more complex. Essentially, the result is that teenage motherhood has an odds ratio of about five and motherhood in the early twenties of about three and a half for those who were not fairly or clearly poor as girls, but these odds ratios do increase further when the poverty level was higher to about 7.5 for teenage mothers and about 5 for those who became mothers at 20-22. The association of social housing with levels of childhood poverty is stronger for those who had a birth at ages 23-32, 
with the baseline odds of 1.00 rising to 1.59 for any experience of childhood poverty and further to 2.27 for those who were fairly or clearly poor as children.

\section{Summary}

\subsection{Main findings}

We have shown that there are clear and statistically strongly significant associations for a range of adult outcomes with age at first birth, even after controlling for levels of childhood poverty and a very wide range of other childhood background factors. Moreover, we have demonstrated that the widest gulf in adult outcomes occurs for those who enter motherhood early (before age 23), though further reinforced for teenage motherhood for most adult outcomes. We have also shown that it is any experience of childhood poverty that is most clearly associated with adverse outcomes in adulthood, with additional reinforcement for higher levels of childhood poverty only being significant for a few outcomes.

In broad terms and given the limitations of sample size, we found little evidence to suggest that there were further differences in the odds of adult outcomes for more detailed sub-division of ages at birth (explicitly 23-26 and 27-32, and under 18). We also find some evidence of interactions of any experience of childhood poverty with early childbearing for three outcomes (extra-marital birth, lone parenthood, and living in social housing), with the results pointing towards age at first birth effects dominating childhood poverty effects for earlier ages at first birth, but with childhood poverty effects having an impact for those who entered motherhood later; these results correspond quite well with those shown in raw form, without other childhood controls, in Table 3.

Much discussion of consequences of early motherhood focuses on teenage mothers. The results presented here show a clear contrast between those who become mothers before age 23 with those who do not. For young women in particular, it is probable that early parenthood is directly implicated in the genesis of adverse outcomes later in life, through limiting opportunities and choices. Early births are more likely to have taken place outside marriage and there is also ample evidence that early partnerships are much more likely to break down. Both of these factors are clearly implicated in much higher risks of having experienced lone parenthood by age 33. It is generally young mothers, rather than young fathers, who are the lone parents. Early parenthood is 
also more likely to precipitate an entry into social housing and to limit employment and career opportunities. Teenage motherhood is clearly even more strongly related to these factors.

Early motherhood is also closely associated with lack of qualifications, although we fully realise that failure at school (surely well captured by the combined test scores) often occurs before entry into motherhood; what is perhaps surprising, in view of the explanatory power of the childhood variables for lack of qualifications at age 33, is that there still remains a clear association with early parenthood.

In addition, we find that early mothers are also more likely to be in receipt of non-universal benefits, even at age 33 - at least ten years after the first birth for all early mothers and more than 13 years later for teenage mothers. Young mothers are also shown to be considerably more likely to have low household income at age 33, and to lack a telephone in the household: both are probably important elements of being socially excluded. Moreover, early childbearing is also clearly associated with poorer physical and mental health at age 33, which is well after the entry into motherhood. We cannot claim that all of these associations with early parenthood are directly or only the result of early childbearing, since no other adult pathways are included in our models, but we can be reasonably confident that these associations arose during adulthood, given the powerful range of childhood controls used in our models.

\subsection{Across the 'Great Divides': early motherhood and any childhood poverty}

We have shown that becoming a mother before age 23 and that any experience of childhood poverty are clear dividing points in differentiating risks of adverse outcomes in later adulthood. In Table 9 we show the odds ratios for combinations of age at first birth and levels of childhood poverty, net of the wide range of other childhood factors (some of which also have high odds ratios).

Figure 2 takes the dividing points of any childhood poverty and of a birth before age 23 and presents the odds ratios from Model 3A (without interaction terms) for four combinations: the reference group with a first birth at ages 23-32 and no childhood poverty, with odds of one; those who had a first birth before age 23, but did not have any experience of childhood poverty; those who experienced any childhood poverty, but had their first birth aged 23-32; and those who both experienced any childhood poverty and had their first child before age 23. 
Table 9: Odds ratios for experiencing adult outcomes by combinations of age at first birth and level of childhood poverty, net of other childhood controls (Model 3A)

\begin{tabular}{|c|c|c|c|c|c|c|}
\hline & Not poor & $\begin{array}{l}\text { Probably } \\
\text { not poor }\end{array}$ & $\begin{array}{c}\text { Some } \\
\text { poverty }\end{array}$ & Fairly poor & $\begin{array}{c}\text { Clearly } \\
\text { poor }\end{array}$ & All missing \\
\hline \multicolumn{7}{|c|}{ Extra-marital birth } \\
\hline Teenage & 4.51 & 4.51 & 5.84 & 5.84 & 5.84 & 4.51 \\
\hline $20-22$ & 2.17 & 2.17 & 2.81 & 2.81 & 2.81 & 2.17 \\
\hline $23-32$ & 1.00 & 1.00 & 1.30 & 1.30 & 1.30 & 1.00 \\
\hline \multicolumn{7}{|c|}{ Ever lone parent } \\
\hline Teenage & 8.32 & 8.32 & 8.85 & 8.85 & 8.85 & 8.32 \\
\hline $20-22$ & 4.43 & 4.43 & 4.71 & 4.71 & 4.71 & 4.43 \\
\hline $23-32$ & 1.00 & 1.00 & 1.06 & 1.06 & 1.06 & 1.00 \\
\hline \multicolumn{7}{|c|}{ Social housing } \\
\hline Teenage & 4.28 & 4.28 & 5.42 & 7.70 & 7.70 & 4.28 \\
\hline $20-22$ & 2.89 & 2.89 & 3.65 & 5.20 & 5.20 & 2.89 \\
\hline $23-32$ & 1.00 & 1.00 & 1.27 & 1.80 & 1.80 & 1.00 \\
\hline No birth & 0.74 & 0.74 & 0.94 & 1.34 & 1.34 & 0.74 \\
\hline \multicolumn{7}{|c|}{ Any benefits } \\
\hline Teenage & 2.42 & 2.42 & 3.06 & 3.06 & 3.06 & 2.42 \\
\hline $20-22$ & 1.90 & 1.90 & 2.40 & 2.40 & 2.40 & 1.90 \\
\hline $23-32$ & 1.00 & 1.00 & 1.27 & 1.27 & 1.27 & 1.00 \\
\hline No birth & 0.45 & 0.45 & 0.57 & 0.57 & 0.57 & 0.45 \\
\hline \multicolumn{7}{|c|}{ No qualifications } \\
\hline Teenage & 2.73 & 2.73 & 4.16 & 4.16 & 6.33 & 2.73 \\
\hline $20-22$ & 1.99 & 1.99 & 3.02 & 3.02 & 4.59 & 1.99 \\
\hline $23-32$ & 1.00 & 1.00 & 1.52 & 1.52 & 2.31 & 1.00 \\
\hline No birth & 1.00 & 1.00 & 1.52 & 1.52 & 2.31 & 1.00 \\
\hline \multicolumn{7}{|c|}{ Low household income } \\
\hline Teenage & 1.92 & 1.92 & 2.58 & 2.58 & 3.79 & 1.92 \\
\hline $20-22$ & 1.39 & 1.39 & 1.87 & 1.87 & 2.76 & 1.39 \\
\hline $23-32$ & 1.00 & 1.00 & 1.35 & 1.35 & 1.98 & 1.00 \\
\hline No birth & 1.45 & 1.45 & 1.94 & 1.94 & 2.86 & 1.45 \\
\hline
\end{tabular}




\begin{tabular}{lcccccc}
\hline No telephone & & & & & & \\
Teenage & 2.21 & 2.21 & 4.04 & 4.04 & 4.04 & 2.21 \\
20-22 & 2.21 & 2.21 & 4.04 & 4.04 & 4.04 & 2.21 \\
23-32 & 1.00 & 1.00 & 1.83 & 1.83 & 1.83 & 1.00 \\
No birth & 1.00 & 1.00 & 1.83 & 1.83 & 1.83 & 1.00 \\
General ill-health & & & & & & \\
Teenage & 1.42 & 1.42 & 1.74 & 1.74 & 1.74 & 1.42 \\
20-22 & 1.42 & 1.42 & 1.74 & 1.74 & 1.74 & 1.42 \\
23-32 & 1.00 & 1.00 & 1.23 & 1.23 & 1.23 & 1.00 \\
No birth & 1.00 & 1.00 & 1.23 & 1.23 & 1.23 & 1.00 \\
Current smoker & & & & & & \\
Teenage & 2.45 & 2.45 & 3.07 & 3.07 & 3.07 & 2.45 \\
20-22 & 1.86 & 1.86 & 2.33 & 2.33 & 2.33 & 1.86 \\
23-32 & 1.00 & 1.00 & 1.25 & 1.25 & 1.25 & 1.00 \\
No birth & 1.40 & 1.40 & 1.75 & 1.75 & 1.75 & 1.40 \\
Malaise & & & & & & \\
Teenage & 1.86 & 1.86 & 2.66 & 2.66 & 2.66 & 1.86 \\
20-22 & 1.86 & 1.86 & 2.66 & 2.66 & 2.66 & 1.86 \\
23-32 & 1.00 & 1.00 & 1.43 & 1.43 & 1.43 & 1.00 \\
No birth & 1.00 & 1.00 & 1.43 & 1.43 & 1.43 & 1.00 \\
Unsatisfactory life & & & & & & \\
Teenage & 1.46 & 1.46 & 1.46 & 1.46 & 2.03 & 2.42 \\
20-22 & 1.46 & 1.46 & 1.46 & 1.46 & 2.03 & 2.42 \\
23-32 & 1.00 & 1.00 & 1.00 & 1.00 & 1.39 & 1.65 \\
No birth & 1.34 & 1.34 & 1.34 & 1.34 & 1.86 & 2.22 \\
\hline \hline & & & & & & \\
\hline
\end{tabular}




\section{Figure 2: Across the Great Divides: Early Motherhood and Any Childhood Poverty}

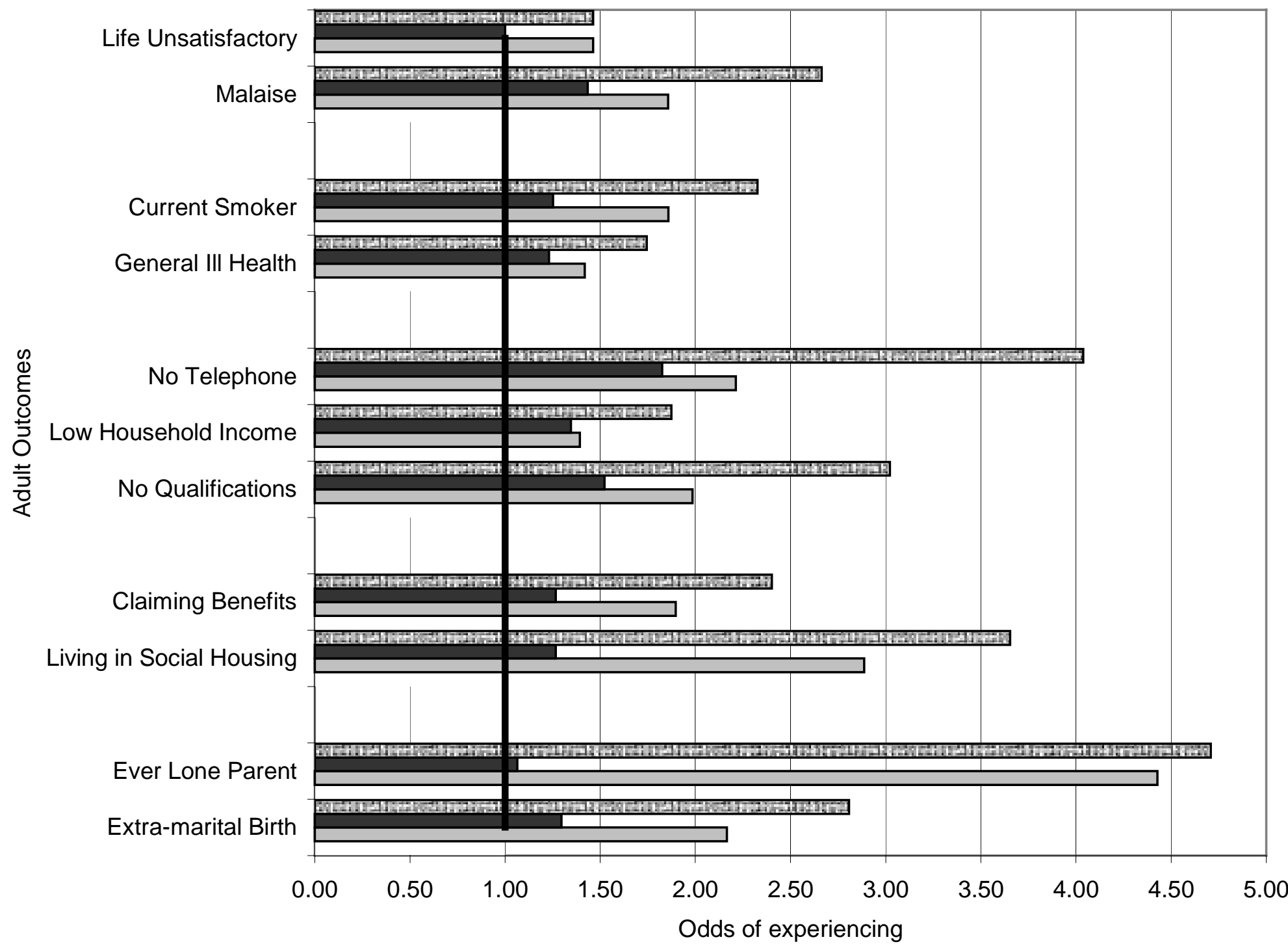

Eater Some Childhood Poverty \& First Birth Before 23

$\square$ Some Childhood Poverty, First Birth 23-32

$\square$ First Birth Before 23, No Childhood Poverty

Linear (No Childhood Poverty, First Birth 23-32) 
Figure 3: At the Extremes: Teenage Motherhood and Clear Childhood Poverty

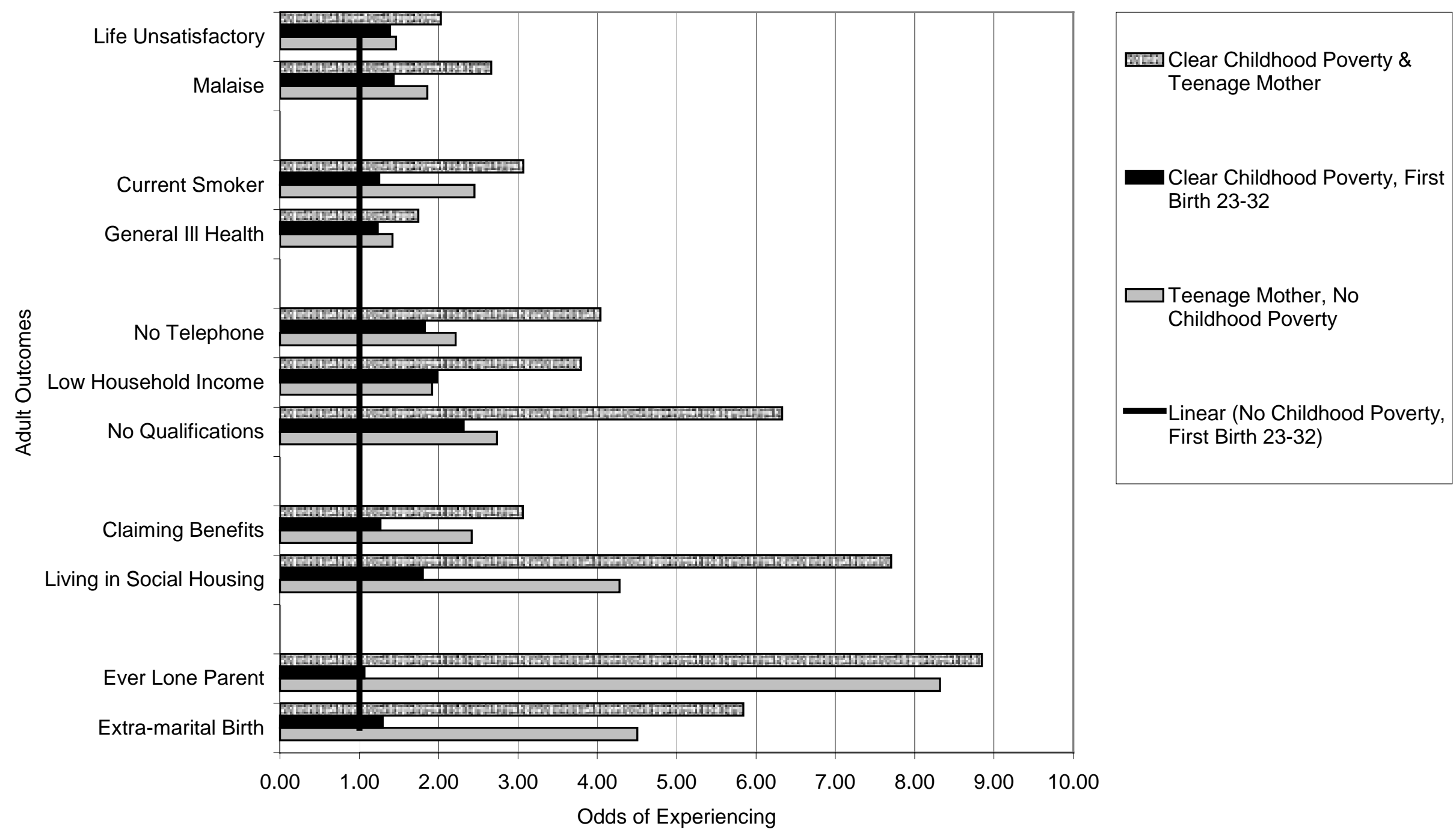


The first striking feature of Figure 2 is that an early first birth without childhood poverty has a higher odds ratio for every adult outcome than does experience of any childhood poverty with a later birth: this is especially true for the demographic outcomes, the welfare outcomes, and current smoking; the differences are smaller for household income and access to a telephone.

Although the effects of childhood poverty are generally weaker, they nevertheless reinforce the effects of age at first birth to generate quite sizeable odds ratios for the combination: early mothers who were poor sometime during childhood are over four times as likely to have been a lone parent and to lack a telephone in their household; over three times as likely to live in social housing and to have no qualifications; more than twice as likely to have had an extra-marital birth, be claiming non-universal benefits, to be cigarette smokers, and to have high malaise scores.

\subsection{At the extremes: teenage motherhood and clear childhood poverty}

In Figure 3 we show similar results for combinations of teenage motherhood and clear childhood poverty. In general, except for some outcomes (living in social housing, lack of qualifications, low household income, and reporting an unsatisfactory life), there are no changes in the odds ratios for level of childhood poverty for the move from any experience to clear poverty. In contrast, the shift to teenage motherhood further increases the odds ratios for most adult outcomes, the exceptions being lack of a telephone, general ill health, and the two mental health outcomes. With only one minor exception, for low household income, the odds ratios for having been clearly poor as a child are lower than those for being a teenage mother; these differences are particularly large for the demographic and welfare outcomes and for cigarette smoking.

For the two demographic outcomes, having had an extra-marital birth and ever having been a lone parent, the effects of clear childhood poverty are small, and it is the demographic behaviour through teenage first birth which has the dominant impact on the odds ratios.

$>$ Teenage mothers are over eight times as likely to have been lone parents by age 33 as are those who became mothers aged 23-32 and, for this outcome, childhood poverty levels are more or less irrelevant: regardless of the level of childhood poverty, all teenage mothers are at much greater risk of becoming lone parents.

$>$ Teenage mothers are also at much greater risk (nearly five-fold, compared with those having their first birth aged 23-32) of having an extra-marital birth and, once again, levels of childhood poverty 
are relatively unimportant, as became especially clear when interaction terms were included in our models.

For the welfare related outcomes, it is again a teenage first birth which dominates the effects of childhood poverty, with particularly strong associations for social housing.

$>\quad$ In Figure 3, we see that having been a teenage mother, but not poor during childhood raises the risk of being in social housing at age 33 more than four-fold (compared with a first birth aged 2332); having been clearly poor as a child almost doubles the risk of being in social housing at age 33 (compared with no experience of childhood poverty); the combination of clear poverty during childhood and teenage motherhood is thus associated with a near eight-fold risk of being in social housing, many years after the teenage birth.

$>\quad$ Moreover, teenage motherhood is also associated with two-and-ahalf times the risk of claiming non-universal benefits at least 13 years later; once again, this is only mildly reinforced by experience of childhood poverty (a 27\%) increase, leading to tripling of risk of being on benefits at age 33 for the poorest girls who also became teenage mothers.

The next cluster of outcomes at age 33 that we consider are lack of qualifications, low household income, and lack of a telephone in the household; these thus represent lack of human capital, adult poverty, and a combination of poverty and social isolation, respectively. For all three of these outcomes the excess risks associated with clear childhood poverty and with teenage motherhood are of similar magnitude, involving an approximate doubling of risk for either (compared with the baseline groups of no childhood poverty and of having a first birth aged 23-32), though slightly higher for lack of qualifications.

Given that the results are net of educational test scores during childhood and parental interest in education, among other controls, it is remarkable that strong associations of lack of qualifications at age 33 persist both for those who experienced clear childhood poverty and for those who became teenage mothers. Teenage mothers were 2.7 times as likely to lack qualifications at age 33, though this may cause as much as effect; the poorest girls were 2.3 times as likely to lack qualifications; in combination, these two factors were associated with over six times the risk of being unqualified at age 33 .

$>\quad$ Net of all other childhood factors, teenage mothers or girls who grew up in poverty are both about twice as likely (as those who 
had a first birth aged 23-32 or were not poor as children) to live in poor households at age 33 and to lack access to a telephone in that household; poor girls who became teenage mothers have quadruple the risks for both these outcomes.

Turning to the outcomes concerned with physical and mental health at age 33, we see the smallest overall associations for the two nonspecific self-reported measures: general health poor or fair, and a low rating for life satisfaction on a scale from zero to ten. The specific negative health behaviour, cigarette smoking, and the more elaborate measure of mental well-being on the malaise inventory, both show larger associations.

$>\quad$ Teenage mothers are two and a half times as likely to be cigarette smokers at age 33 than those who delay their first birth to ages 2332 ; there is a small additional association with childhood poverty $(25 \%)$, which increases the overall propensity to cigarette smoking to three times that for women who had their first birth aged 23-32 and were not poor during childhood.

$>$ Teenage mothers were also almost twice as likely to give indications of poor mental health (high scores on the malaise inventory - indicative of depression), and this was reinforced further (by $43 \%$ ) for those who were poor as girls, leading to a two and two-thirds excess risk of malaise for teenage mothers who were poor as girls, compared with those who were not poor as children who had their first birth when aged 23-32.

$>$ Self-reported general poor or fair health at age 33 and a low life satisfaction score were around twice as likely for poor girls who became teenage mothers than for their peers who were not poor as girls and had their first birth aged 23-32.

Thus, on the whole, we have seen that age at first birth shows more powerful associations with most adverse adult outcomes considered here than does experience of childhood poverty. Demographic behaviour (timing of first birth) is very powerfully related to the two demographic outcomes, but also to the propensity to live in social housing; it is also considerably more strongly related to receipt of non-universal benefits and to cigarette smoking, and somewhat more so for malaise. Childhood poverty is about as powerful a correlate as the timing of first birth with respect to poverty at age 33, as measured by low household income and lack of a telephone in the household, as well as for lack of qualifications. Associations with vaguer self-reported physical or mental well-being were weaker. 
Although the effects of childhood poverty are generally weaker, they nevertheless reinforce the effects of age at first birth to generate quite sizeable odds ratios for the combination. Teenage mothers who were clearly poor during childhood are: over eight times as likely to have been a lone parent; over seven times as likely to live in social housing; about six times as likely to have no qualifications and to have had an extra-marital birth; about four times as likely to lack a telephone in their household and to have low household income; over three times as likely to be in receipt of non-universal benefits and to be current smokers ; and more than twice as likely to have high malaise scores and to report their lives as unsatisfactory.

\section{Conclusion}

From our analyses it is tempting to draw the conclusion that childhood poverty begets adult poverty (including lack of human capital) and that demography begets demography. However, the power of the associations of age at first birth with both living in social housing and receipt of non-universal benefits at age 33 , as well as the equality of the odds ratios for age at first birth with those for childhood poverty on adult poverty, no telephone, and lack of qualifications, does suggest that early childbearing has more profound and far-reaching consequences for the lives of the women involved. Early parenthood for young women is likely to have much more direct implications for lack of opportunity and choice than for young men. Whilst we have not here examined the subsequent pathways into adult social exclusion for early mothers, the associations found in this study are often very powerful indeed. 


\section{References}

CASE and HM Treasury (1999), Persistent Poverty and Lifetime Inequality: The Evidence, CASEreport 5 and HM Treasury Occasional Paper, No.10. London: CASE and HM Treasury.

Ferri, E (ed) (1993), Life at 33: The fifth follow-up of the National Child Development Study. London: National Children's Bureau.

Gregg, P, Harkness, S, Machin, S and Thomas, J (1999), Child Development and Family Income. York: Joseph Rowntree Foundation.

HM Treasury (1999), Tackling Poverty and Extending Opportunity. London: HM Treasury.

Hobcraft, JN (1998), Intergenerational and Life-Course Transmission of Social Exclusion: Influences of Childhood Poverty, Family Disruption, and Contact with the Police, CASEpaper 15, Centre for Analysis of Social Exclusion. London: London School of Economics.

Kiernan, KE (1980), "Teenage motherhood: Associated factors and consequences", Journal of Biosocial Science, 12(4).

Kiernan, KE (1995), Transition to parenthood: Young mothers, young fathers: associated factors and later life experiences, STICERD Discussion Paper WSP/113. London: London School of Economics.

Kiernan, KE (1997), "Becoming a Young Parent: A longitudinal study of associated factors", British Journal of Sociology, 48(3).

Richman, N (1978), "Depression in mothers of young children”, Journal of the Royal Society of Medicine, 71: 489-493.

Rutter, M, Tizard, J and Whitmore, K (1970), Education, Health and Behaviour. London: Longman.

Rutter, M, Tizard, J and Graham, P (1976), "Isle of Wight Studies: 19641974", Psychological Medicine, 16: 689-700.

Social Exclusion Unit (1999), Teenage Pregnancy, Cm 4342. London: TSO.

Wadsworth, MEJ (1991), The Imprint of Time: Childhood History and Adult Life. Oxford: Clarendon Press. 